Portland State University

PDXScholar

$9-28-2021$

\title{
Online Activism and Real Life Environmentalism
}

Emily Grace Anderson

Portland State University

Follow this and additional works at: https://pdxscholar.library.pdx.edu/open_access_etds

Part of the Communication Commons, and the Environmental Studies Commons Let us know how access to this document benefits you.

\section{Recommended Citation}

Anderson, Emily Grace, "Online Activism and Real Life Environmentalism" (2021). Dissertations and Theses. Paper 5808.

https://doi.org/10.15760/etd.7679

This Thesis is brought to you for free and open access. It has been accepted for inclusion in Dissertations and Theses by an authorized administrator of PDXScholar. Please contact us if we can make this document more accessible: pdxscholar@pdx.edu. 
Online Activism and Real Life Environmentalism

\author{
by \\ Emily Grace Anderson
}

A thesis submitted in partial fulfillment of the requirements for the degree of

\author{
Master of Science \\ in \\ Communication
}

Thesis Committee:

Brianne Suldovsky, Chair

Jeffrey Robinson

Erin Spottswood

Portland State University

2021 


\begin{abstract}
Past and present human activities have created and accelerated an array of environmental catastrophes and various systems in the environment remain under threat as a result of human behavior. In hopes of mitigating environmental consequences, a social movement has arisen to encourage people to behave in ways that are more environmentally sustainable. Research shows that individual behavior choices impact the environment, and this influence can be used to positively affect the environment through engagement in pro-environmental behavior. Like with many other social movements, the internet has been a tool in spreading awareness of a cause and allowing people the opportunity to engage in online activism. This paper considers the relationship between engaging in online activism via social media and pro-environmental behavior. Prior literature has mixed findings regarding this relationship; some have criticized engaging in online activism for its potential to replace, rather than complement, other forms of participation in a cause, described by a concept known as slacktivism. In addition to exploring this relationship, this paper focuses on motivation for social media use as an explanation for the relationship found between online activism and proenvironmental behavior. Correlation analyses indicate there is a significant positive correlation between online activism and pro-environmental behavior. The data also reveals a significant positive relationship between social media use motivated by altruism and
\end{abstract}


pro-environmental behavior, aligning with prior research about altruistic values and pro-environmental behavior. 


\section{Acknowledgements}

Thank you to parents for their endless support and encouragement. Thank you to my advisor, Dr. Suldovsky, for being an anchor throughout not just this whole project, but also grad school. Thank you to my committee members, Dr. Spottswood, Dr. Robinson, and Dr. Suldovsky, for their support and guidance throughout this project. Thank you to Dr. Shaker for inspiring my interest in higher education, giving me the tools to make it accessible, and helping me understand my full potential as an academic. Thank you to my cohort, as well as members of the 2022 cohort, for so much support and inspiration. A special thank you to Jamie Knopf for being my rock through grad school and beyond. 


\section{Table of Contents}

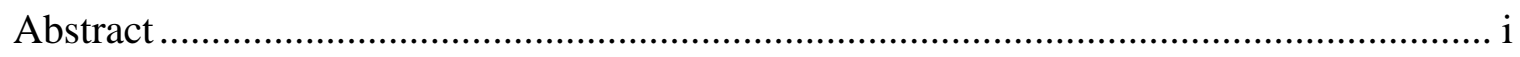

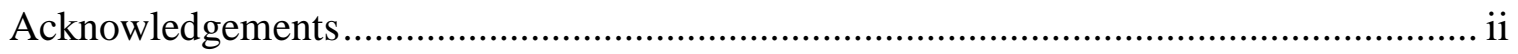

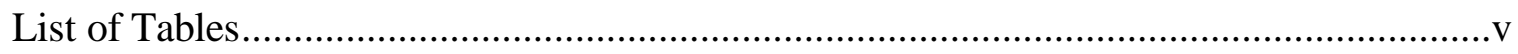

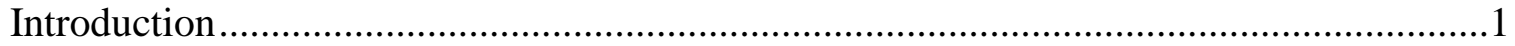

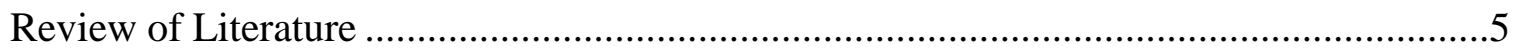

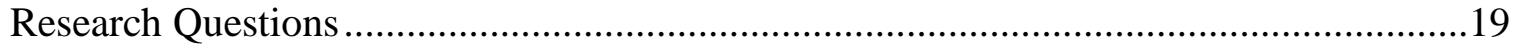

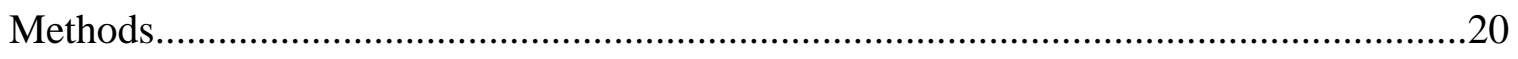

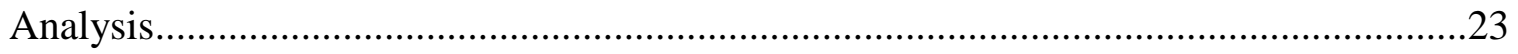

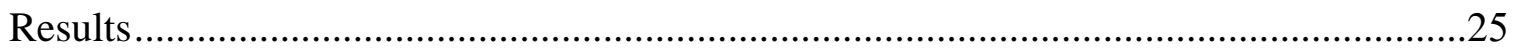

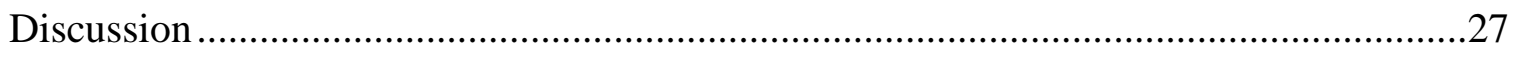

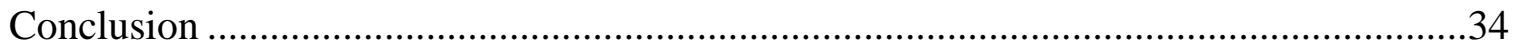

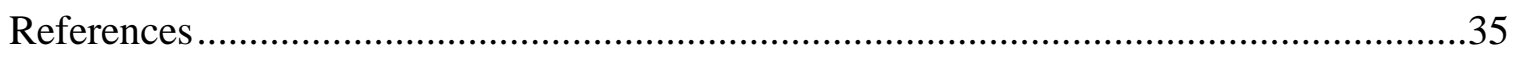

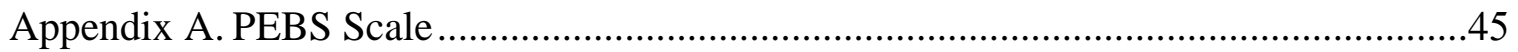

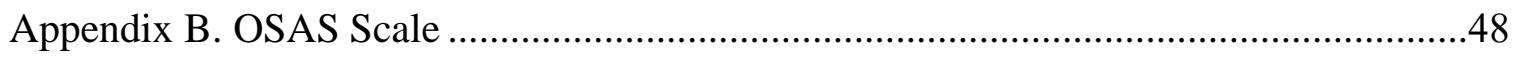

Appendix C. Motivation for Social Media Use ....................................................50

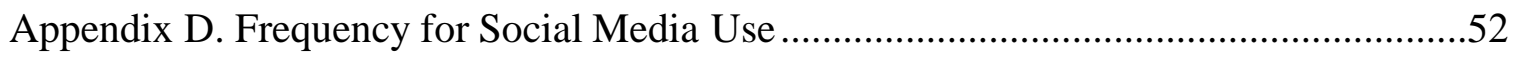

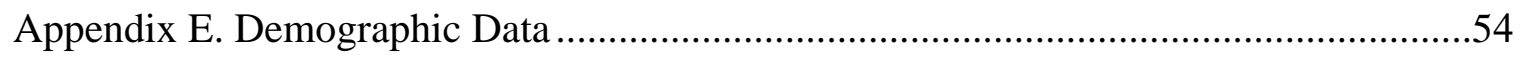




\section{List of Tables}

Table 1 Pro-environmental Behavior Subscale Statistics. ........................................... 24

Table 2 Correlation Matrix for Independent Variables................................................ 26 


\section{Introduction}

Concerns over the natural environment to varying degrees have been present throughout history, with reports of concerns about environmental hazards such as pollution occurring in Westernized nations during the Industrial Revolution (Fleming \& Knorr, n.d.). Throughout time, the harmful impact of human behavior on the environment has become an evident and constantly increasing threat to the earth's carrying capacity (Blok et al., 2015). This has been occurring through a simultaneous process: the natural resources humans rely on such as air, water, and land, are being polluted as those resources are also being continually depleted as a result of human use (Lehman and Geller, 2004; Blok et al., 2015). Because present actions will contribute to the preservation or further destruction of the environment, scholarship should focus on how humans can change their behavior to best serve the protection of the environment (Vicente-Molina., Fernández-Sáinz, \& Izagirre-Olaizola, 2013).

Today's modern environmental movement includes a broad range of pro-environmental topics, including sub-movements such as conservation, climate change resistance, sustainable business practices, and environmental justice. While the specific objectives of the different sectors are unique to each field, the main goals of these sub-movements are united in shifting the behavior of individuals and organizations in ways that benefit the natural environment (Stern, 2000). One of the primary ways to consider individual and collective action in service of the environmental movement is in the context of pro-environmental behavior. Pro-environmental behavior details a variety of different behaviors that are more sustainable than more socially accepted and dominant 
behaviors, including actions like purchasing more environmentally friendly versions of products, engaging in environmental activism, and participating in ways to improve the surrounding environment such as community clean-up events. After exploring the concept of pro-environmental behavior, I detail the ways in which social media use, especially for the purpose of engaging in online activism, relates to pro-environmental behavior.

Online networks of communication present new characteristics of socialization and information dissemination. In their current form, these online platforms give users greater freedom from government or corporate control than other means of communication used in the past. Castells (2015) summarizes these characteristics by saying: "In our time, multimodal, digital networks of horizontal communication are the fastest and most autonomous, interactive, reprogrammable, and self-expanding means of communication in history." (p. 15) The presence of and reliance on social media in the modern age has invigorated comprehensive research into the ways that individual-level interactions and societal-level patterns have been affected by online communication, specifically through the channels of social media. One avenue of research examines the ways that social movements have been affected by social media, and what roles social media can play in facilitating both online and offline involvement in these movements. This is the underlying focus of the following paper.

One primary criticism of social media in the context of activism and other actions is a phenomenon known as slacktivism, which is founded on criticisms of online activism as being a "lazy" form of activism. Slacktivism refers to actions that require relatively 
low effort or engagement, which can be abundant on social media platforms through mechanisms such as liking, sharing, and certain ways of posting about social movements. These actions overlap with the behaviors considered to be online activism, and research on these topics use a variety of terms to describe the same concept; this paper will primarily use the term online activism, but may also use the terms slacktivism, token support, or low-threshold activism depending on the literature being discussed. Former literature outlines the difference between activism and slacktivism, suggesting that activism requires more meaningful effort, such as donating, protesting, organizing and joining activist groups, etc., whereas slacktivism typically revolves around the public demonstration of participation in a movement and beyond that, putting in no further effort, commitment, or attachment to the outcomes of the movement. This paper will refer to the term pro-environmental behavior to refer to behaviors that are typically carried out offline and are described as more meaningful participation in a cause, but may also use the terms meaningful support or offline activism depending on the terms used by the literature being explored (Kristofferson, White, \& Peloza, 2014)

The secondary focus of this research is motivation for social media use. Because the definitions of slacktivism point to the motivations for social media use as an indicator of participation in offline activism, further exploration of this relationship is warranted. The motivations for social media use are based on a typology developed by Yankah et al. (2017), developing these motivations into five categories: entertainment, personal utility, convenience, information-seeking, and altruism. Some studies find that the motivation for social media use is related to engagement in pro-environmental behavior, but more 
research is needed to confirm this. Ultimately, as environmental protection is becoming more politicized and increasingly threatened, it is useful to consider all avenues of participation in the environmental movement (Bouleau, 2019). The following paper focuses on the ways in which people engage in the environmental movement through online activism and participation in pro-environmental behavior. 


\section{Review of Literature}

Bleys, Defloor, Van Ootegem, and Verhofstadt (2018) explore the ecological footprint, (also referred to as carbon footprint) resulting from individual behavior choices. They found that food choices, use of recyclable materials, and lower electricity consumption are positively correlated with a reduced ecological footprint, suggesting that individual-level behaviors can have a significant impact on improving environmental outcomes. Of course, the extent of negative environmental impact can vary across populations and nations. Gore (2020) found that for individuals in the top 10 percent of citizens in Europe, behaviors such as motorized vehicle use accounts for the highest percentage of carbon emissions. Furthermore, they found that "reducing the per capita footprint of the richest $10 \%$ to the $1.5 \mathrm{C}$-consistent level by 2030 would cut annual carbon emissions by over a third (>15Gt), and even reducing it just to the level of the EU average (8.2t/year) would cut annual emissions by over a quarter" (Gore, 2020, p. 6). Additionally, Gore (2020) focuses on a population of individuals in the United States is important considering the figures generated from country comparisons. For example, individuals in the wealthiest 10 percent of citizens in India have a quarter of the carbon footprint than the poorest 50 percent of citizens in the United States (Gore, 2020, p. 2).

Furthermore, the poorest $50 \%$ of citizens in China emit one-third of the total carbon emissions of the wealthiest $10 \%$ of United States citizens (p. 2). Even so, it is clear that pro-environmental behavior at the individual level is a significant contributor to environmental degradation. 
Pro-environmental behavior refers to "a range of behaviors that benefit the natural environment, enhance environmental quality, or harm the environment as little as possible" (Larson et al., 2015, p. 112; Steg \& Vlek, 2009). Other terms that have been used in research to describe this concept include green consumption behavior, environmentally responsible behavior, environmentally conscious behavior, and environmental activism (Lee, Kim, Kim, \& Choi, 2014, p. 2098). Pro-environmental behavior has been most commonly measured through the use of self-reported behaviors and by the method of surveys, and Stern (1999) devised the concept into three primary categories of behavior: green purchase behavior, good citizenship behavior, and environmental activist behavior (See also: Lee et al., 2014). Green purchase behavior has to do with the prioritization of how a product or service negatively impacts the environment in the decision to purchase it (Moisander, 2007; Scheffer, 1991). While this kind of green consumerism is crucial to conserving natural resources, it is less intentional and motivated than other behaviors because it can occur accidentally and without the goal of helping the environment.

Good citizenship behavior, on the other hand, refers to behaviors that are not purchase-related but have a positive environmental impact (Lee et al., 2014). Some examples include behaviors such as recycling, composting, or participating in community clean-up events. Good citizenship behavior in the context of pro-environmental behavior means that, rather than the businesses or manufacturers who are taking the environmentally helpful action, it comes down to the choice of the individual and is therefore usually done with the goal of environment or community preservation. 
Therefore, it is considered to be "...a more active form of pro-environmental behavior than green purchase behavior because it requires some extent of personal cost or sacrifice and has a more direct effect on environmental protection or preservation." (Lee et al., 2014, p. 2098).

Environmental activist behavior requires a collective action that involves communicating with the representatives of governments and corporations to enact policy that would work to improve conditions that are harmful to the environment. Some examples of environmental activist behavior include membership with pro-environmental groups, engaging in overt political actions, intentionally performing pro-environmental behaviors and encouraging others in doing so, and participating in sub-movements towards creating pro-environmental policies (Lee et al., 2014). More specific examples of environmental activist behavior are the waves of protests in the United States starting with Earth Day in 1970, the People's Climate March of 2014 and 2017, March Against Monsanto, Kyoto Now!, No DAPL, and the Global Climate Strikes of 2019.

\section{Online Activism and Social Movements}

Today, much of the activities involved in online activism are taking place through social media platforms. Social media is becoming more of a fixture in day-to-day life than most forms of social interaction, with its presence vastly changing the degree and mode of access we have to other people, information, and ideas (Castells, 2015). This democratization of access has led to a large increase in the exchange and sharing of ideas, even across geographical boundaries. Thus, it has become foundational in the communication of many kinds of organizations, making it a relevant point of focus for 
the role that social media can play in social movements (Amant, 2017, p. 10). In order for social movements to develop, Castells (2015) states that they require a scenario in which "...the emotional activation of individuals connect(s) to other individuals" (p. 14). Due to the scope of the internet, this activation of emotion happens at a more rapid pace and on a larger scale than former communication mediums.

In the past, other communication mediums such as flyers, newspapers, word of mouth, rumors, etc., were fundamental to the organization of social movements. Now, the internet offers a way for people to communicate and even has the potential to do so beyond the monitoring eyes of governments and corporations through anonymous browsers such as The Onion Router or ExpressVPN. Additionally, the internet allows a message to be amplified and accessed nearly instantly by vast numbers of people. Throughout history and continuing to the current times, social movements have had the effect of creating and determining different values, goals, or priorities typically set by society's institutions and shifting them to reflect the needs of the public body. This redistributes power from an authoritative minority to the people, and it is especially impactful in the age of the internet due to the ability for communication to take place with less restraint, censorship, and monitoring (Castells, 2015)

Due to these characteristics, activism by way of the internet has the potential to strengthen democracy. Loader and Mercea (2011) state that the internet has provided new avenues for participation, governance, voting, and other general areas of democratic involvement. Additionally, greater representative democracy can be supported by the internet because it includes multi-directional flows of communication that allow more 
access to feedback, information, and transparency (p. 43). Similarly, some groups are able to have greater participation in democracy through the internet due to what are typically systemic restraints. For example, Correa, Hinsley, and De Zuniga (2010) found that women are more likely to be users of social media than men are, meaning that they have greater access to social movements online. Murthy (2018) notes that “...this may have major implications for movements which are organizationally gendered, ultimately enabling women to have a more democratic involvement in some social movements" (p. 2). This idea of access and representative democracy can be applied to most groups facing political oppression and lack of representation. One of the strongest actualizations of democratic participation is achieved through online activism.

One example of online activism comes from the social movements ignited through organizing on Facebook. Specific cases such as the Occupy Wallstreet movement, the Arab Spring, Black Lives Matter, and the Dakota Access Pipeline protests demonstrate the way in which social media platforms have provided a place for movements online to quickly develop into offline action (Harlow, 2012; Murthy, 2018). This function of social media can have major implications for large-scale societal structures. For example, the Black Lives Matter movement which was ignited on social media after the hashtag “\#blacklivesmatter" was used, created in response to George Zimmerman's acquittal after he killed an unarmed teenager named Trayvon Martin. Carney (2016) found that both online and offline activism and protests against the absence of legal consequences in Zimmerman's case and the subsequent Black Lives Matter activism heavily influenced "national discourse about race" and has advanced into 
a globally recognized movement (p. 180; See also: Murthy, 2018).

One way that social media has brought strength to social movements is its logistical influence on protesting and organization. While it is considered mainly to be a tool for communication and idea exchange, some social media platforms such as Twitter have been shown to be a primary "organizing mechanism" that shapes the structure of a social movement, not just the communication occurring within it (Segerber \& Bennett, 2011; Murthy, 2018). Additionally, social media facilitates protests by telling people where to go and when. It can also help the process of successfully organizing in person by providing contextual information to protest-goers, potentially shedding light on the conditions of the protest and what people can expect should they go. For example, in the No Dakota Access Pipeline movement, people all over the world used social media to "check in" online, allowing them to use GPS tracking to help the activists at the protest sites evade police interference (Worland, 2016). Furthermore, $40 \%$ of protestors who attended the 2014 Ukrainian protests indicated through survey responses that they were invited to the protest by a friend or family member through Facebook (Onuch, 2014). On May 1st, 2012, 44\% of the tweets hashtagged for the Occupy Wallstreet protest included logistical information such as time, location, and crowd size (Jost et al., 2018).

\section{Online Activism or "Slacktivism"?}

While social media has brought a multitude of benefits to users such as information spread, connectivity, and the empowerment of successful social movements, it has also been subject to various criticisms. Some consider it to lead to an overload of information (Meraz, 2009), leaving people without the ability to parse through the input 
and make sense of it without being overwhelmed. Furthermore, it often contains frequent noise which can pose threats to clear decision making and productivity (Hemp, 2009; Muthy, 2018). Some concerns have been that the possibility of inhibiting these functions works against the audience's ability to understand the main message of the movement (Murthy, 2018). Another primary criticism of social media is that it is a weak form of activism that takes little effort or participation, often described by the term slacktivism.

\section{Slacktivism}

Slacktivism, as defined by Christensen (2011), refers to "political activities that have no impact on real-life political outcomes, but only serve to increase the feel-good factor of the participants" (p. 1). Other terms for slacktivism include clicktivism and armchair activism, which was developed in 1937 when Berdyaev said “...more of an armchair revolutionary than a practical one." (p. 94) In modern times, the concept is usually referred to in the context of the internet, which includes making comments, posts, and liking/sharing other posts that are related to some kind of cause or movement. A critical component of slacktivism, which is typically used as a pejorative term, is that it is ineffective in making progress towards the goals of whatever movement it claims to support (Morozov, 2009). The primary criticisms of this behavior are that this type of participation in a movement is short-lived, superficial, and insignificant.

There are several reasons that people may engage in slacktivist behaviors with causes that they wouldn't participate in ways that require offline action. According to Morozov (2009), activism that occurs through social media platforms is commonly not about a person having a strong degree of commitment to the movement, but rather, for the 
purpose of impressing others who are viewing their online activity (p. 186). Another explanation is the Hawthorne Effect, which posits that people behave in more socially desirable ways when they know they are being observed. Social media offers a high degree of social observability due to the fact that most personal profiles are visible to more people than the typical day to day, in-person interactions. A third way to explain this phenomenon and, possibly the most significant criticism, is replacement thesis. In replacement thesis, acts that involve a low degree of effort or commitment to a cause such as liking and sharing on social media replace actions that take more time and engagement (Morozov, 2009; Cabrera, Matias, \& Montoya, 2017).

Kristofferson et al. (2014) explored the effects that engaging in slacktivism has on more involved activist actions. They describe slacktivism as a form of showing token support for a cause and include liking/sharing a post or a page on social media and certain low-effort offline activities as well, including actions like wearing pins/bracelets/other accessories connected to a certain cause. Token support refers to the notion that people are able to be superficially connected and demonstrate their connectedness to a cause with a low amount of effort and cost going into it (Kristofferson et al., 2014, p. 1150). Conversely to token support, Kristofferson et al. (2014) define meaningful support as "consumer contributions that require a significant cost, effort, or behavior change in ways that make tangible contributions to the cause... including donating money and volunteering time and skills" (p. 1150). This type of support is crucial to a successful social movement because it provides the people power and resources to change policy. 
Some studies have demonstrated that there can still be wider impacts resulting from behaviors considered to be within the realm of online token support. For example, Li et al. (2020) analyzed the retweet rate of tweets that contained hashtags related to the Me Too social movement. They found that the retweet rate of tweets containing one or more hashtags was two to three times the rate of tweets that did not contain hashtags, suggesting that certain online activities can multiply the conversational impact of a movement (Li et al., 2020). Similarly, Vie (2014) examined the Facebook page for the Human Rights Campaign which asked supporters of the campaign to add a logo to show support for gay marriage (See also: Cabrera et al., 2017). They found that this action, which may constitute the definition of slacktivism posited by Kristofferson et al. (2017), positively correlated with an increase in discussions of the issue in popular media discourse. They theorized that this discourse posed a challenge to hegemonic dynamics, thus making it effective activism (Vie, 2014; Cabrera et al, 2017). Another study analyzed political engagement during the Czech parliamentary elections in 2013 and found a positive association between people who engaged in typical forms of slacktivism such as liking and sharing posts, and engagement in other forms of political activism such as voting and protesting (Šte`ka \& Mazák, 2014).

Some organizations believe in the potential threats of slacktivism to a movement and have actively worked to combat them. One example is UNICEF Sweden's campaign “Likes Don't Save Lives”, which was looking to garner public support for the fight against diseases in developing nations. They did this with the intention of informing people that social media engagement was not the solution to the problem, but rather, that 
donations and other acts of meaningful support are critical (UNICEF Sweden, 2013). The movement for breast cancer awareness is an example of offline token support. The pink-colored paraphernalia such as clothing and accessories worn in association with the movement have been criticized for their potential to minimize the movement's message. Instead of amplifying the meaningful support given to breast cancer research, it is criticized for creating a "trendy" way to market oneself as being aligned with the movement and can be done without taking steps towards more meaningful action (King, 2006).

One framework applied to the mechanisms behind slacktivist behavior revolves around social observability bias. Kristofferson et al. (2014) theorized that when the situation is occurring under the context of high social observability, then people will show support as a way to engage in impression management (Leary and Kowalsky, 1990). This is because individuals are more focused on their private interests and self, and in the decision-making process of whether or not to provide support for a cause, they will have a greater desire to be consistent with their values and typical behaviors and will, therefore, act more accordingly. In their experiment, they looked at whether people who engage in token support privately would be willing to donate more money to a cause than those who do so in a public, high-observability context.

The findings by Kristofferson et al., (2014) suggest that people engaging in token support in a public context were "...no more likely to provide meaningful support than those who did not engage in an initial token act of support" (p. 1153). In other words, they find that token support through certain kinds of social media engagement, as well as 
token support items like pins and badges, do not generate a more meaningful connectedness or participation in a movement (Kristofferson et al., 2014). They also found that people who are more connected to a cause are more likely to engage in meaningful support than people who do not have a personal connection to the cause. Ultimately, these results point to the idea that concern over the effectiveness of token support through social media with the goal of making progress towards a cause or social movement is warranted, however, findings are inconclusive in understanding whether or not token support is actually working against the progress of a movement.

Importantly, not all research on slacktivism resolves in such a binary duality. Jones (2015) describes the situation as a "both/and", rather than an "either/or" situation. In an analysis of MoveOn, a political action and advocacy organization, Karpf (2012) wrote that low-threshold, particularly online, activism has not replaced other forms of activism; rather, it is a replacement for the kind of "armchair activism" seen in the 1970s. Put differently, online activism is still an important part of social movement progression because it does not replace the activities that would be considered as meaningful support, it enhances it. One example is how signing petitions is not an end to itself, but it does act as a way to gain access to the attention of people who are in positions of power (See also: Cabrera et al., 2017). In summary, online activism has been shown to be a useful component of engagement in offline behaviors aligned with a cause, however, research is limited on the strength of this relationship.

\section{Online Activism and Pro-Environmental Behavior}

While research on this relationship is limited, there have been some mixed 
findings on the role social media specifically plays in the environmental movement and facilitation of pro-environmental behavior. Han and Xu (2020) examined the relationship and found that while traditional media had a negligible effect on pro-environmental behavior change, the strongest influence of this behavior is interpersonal interactions resulting from heightened environmental risk perception that occurs in an online environment. Furthermore, they found that in the context of news through social media, there is a positive relationship between social media use and pro-environmental behavior. This is likely due to the fact that social media spreads information about the social norms and values of different groups. Given this, information about pro-environmental behavior is more quickly and widely distributed. Their study highlights that online activism through social media is an important part of participation in a social movement because people have access to more information and an increased sense of environmental consequences if actions are not taken.

\section{Motivations for Social Media Use and Pro-Environmental Behavior}

Some research finds that the relationship between online activism and pro-environmental behaviors may be mediated by the nature of a person's social media use and their ultimate goals or motivations behind using the platform. For example, Zhang and Skoric (2018) found that for people with a formerly established interest in pro-environmental behavior and policy, or who use Facebook for political reasons, social media use is positively correlated with higher participation in pro-environmental behaviors. When people use social media for strictly relational motivations, some aspects of pro-environmental behavior such as green purchasing behavior are positively 
correlated, while the more intentional behaviors like environmental activism are negatively correlated. They suggest that because social media is a virtual extension of the conversations that occur within relationships, it is likely that social sharing of information is occurring offline as well as a result of information obtained online, further fostering the increase of certain behaviors such as green consumerism. Zhang and Skoric (2018) also suggest that activist behaviors are not increased because they require more meaningful and intentional effort.

Other research focuses on motivations for information sharing about environmental issues or environmentally-related behaviors. For example, Yang, Kahlor, and Griffin (2014) found that information-sharing about the topic of climate change is predicted by and motivated by information-seeking; secondly, information-sharing is motivated by social values. This means that people engaging in information sharing online are more likely to be doing so out of altruistic motives, such as the motive to help people or help social groups communicate and organize more effectively. Social values also refer to connecting with others and participating in conversations.

Former research considers Katz's uses and gratification theory to explain why people use media, which ultimately may connect to the direction and outcomes of their social media use. The uses and grats theory explains that there are needs people seek to have filled through media use and that media use has the potential to gratify them, which can also be applied to the motivations for which people use social media and social networking sites (Raacke \& Raacke, 2008). A wide range of values and motivations have been explored; Pai and Arnott (2013) found that people are motivated to use social media 
by the values of belonging, hedonism, self-esteem, and reciprocity. Additionally, different functions of a social media platform can serve different motivations. Quan-Haase and Young (2010) found that people tend to be motivated by information seeking and entertainment/enjoyment when scrolling through their Facebook feed, but are motivated by relationship maintenance when using the personal messaging function of the site.

Al-Menayas (2015) furthered research of the intersection of uses and grats theory with social media by developing a typology for motivations of social media use. He analyzed responses from a group of 1,327 college students to questions regarding their social media usage, and the data revealed five primary categories for motivations of social media use: entertainment, personal utility, information seeking, convenience, and altruism. They found that a longer history and greater frequency of social media use correlated with the motivations of entertainment and personal utility. Due to the rigorous and comprehensive nature of this typology, it will be utilized as the operationalization for motivations of social media use. 


\section{Research Questions}

Pro-environmental behavior is a key factor in addressing pressing environmental problems, and understanding the way that other behavior variables correlate may highlight key relationships to focus on as a way to increase overall levels of pro-environmental behavior in a population. Research on pro-environmental behavior and online activism is still limited and results are somewhat mixed. Given the lack of clarity regarding the relationship between pro-environmental behavior and online activism, I ask the following research questions:

RQ1: What is the relationship between participation in online activism and pro-environmental behavior?

RQ2: What is the relationship between the use of social media for entertainment and pro-environmental behavior?

RQ3: What is the relationship between the use of social media for personal utility and pro-environmental behavior?

RQ4: What is the relationship between the use of social media for information seeking and pro-environmental behavior?

RQ5: What is the relationship between the use of social media for convenience and pro-environmental behavior?

RQ6: What is the relationship between the use of social media for altruism and pro-environmental behavior? 


\section{Methods}

\section{Participants}

This study surveyed students $(n=163)$ at a large public university in the Pacific Northwest who were enrolled in communication courses. Participants were mostly female $(62 \%)$ and majority white $(52.3 \%)$. Other racial identified included multiracial (12.8\%), Asian (11.0\%), black (5.2\%), American Indian or Alaska Native $(1.2 \%)$, Native Hawaiian or Pacific Islander $(0.6 \%) ; 12.8 \%$ of participants indicated their race was 'other' or preferred not to answer. Participants ranged in age from 18-74 $(\mathrm{M}=18-24)$. Participants were invited to complete a survey during the Winter term of 2021. They were offered extra credit in exchange for their participation.

\section{Measures}

The instrument includes three separate scales to measure

pro-environmental behavior, social media activism, and motivation for using social media along with a set of eleven questions designed to collect demographic information and a scale to measure the frequency of social media use (Junco, 2012).

Pro-Environmental Behavior. Markle (2013) operationalizes pro-environmental behavior using a scale titled the Pro-Environmental Behavior Scale (PEBS). This scale includes 19 items divided into 4 categories: conservation, environmental citizenship, food, and transportation. Conservation refers to the use of natural resources such as water and power. Transportation focuses on the means of an individual's travel, and food relates 
to eating a reduced amount of meat and buying organic food. Lastly, environmental citizenship behavior refers to behavior such as holding an active membership with conservation or environmental groups or donating to these groups (Markle, 2013; Stern, 2000). Some of the responses include a 5-point Likert type scale with $1=$ "never" and $5=$ "always". Markle (2013) reports the reliability for the following sub scales: conservation $(\alpha=.74)$, environmental citizenship $(\alpha=.65)$, food $(\alpha=.66)$, and transportation $(\alpha=$ .62). A reliability analysis performed on the data in the current study shows moderate to low reliability levels among some of subscales: conservation $(\alpha=.60)$, food $(\alpha=.86)$, environmental citizenship $(\alpha=.27)$, and transportation $(\alpha=.52)$.

Online Activism. I measured online activism using the Online Social Activism Scale (OSAS) (Yankah et al., 2017). This scale has 21 items used to measure questions on a 5-point Likert scale ranging from "Strongly disagree" to "Strongly agree". There are also seven questions that have been reverse-coded. For example, Item 1 states: "I frequently express my social and/or political views on social networking sites", whereas Item 12 says: "I rarely initiate conversations about social and/or political issues on social networking sites" (p. 88). The sum of the answers has the highest possible score of 147 . The scale was highly reliable $(\alpha=.95)$

Motivation. Motivation for social media use is measured using a scale by Al-Menayes (2015). These Likert-type items are answerable on a scale of 1 to 5 (1= strongly disagree, $5=$ strongly agree). This scale consists of twenty-two items that cover the following categories and had the following reliability levels: entertainment $(a=0.88)$, 
personal utility ( $a=0.88)$, information seeking $(a=0.87)$, convenience $(a=0.85)$, and altruism $(a=0.90)$. 


\section{Analysis}

The IBM Statistical Package for Social Sciences (SPSS) software was used to organize and analyze the data. The analysis was performed using the item responses from a sample of people after recalling details about their social media use and engagement in a range of pro-environmental behaviors. The survey included the following scales to measure different variables: Markle's (2013) pro-environmental behavior scale, Yankah et al.'s (2017) online activism scale, Al-Menaya's (2015) motivation for social media use scale, and a scale to measure the varying types of social media activities. Along with descriptive statistics, a Pearson's r correlation analysis was used to test how variables in each research question are related.

Pro-Environmental Behavior. This scale involves a variety of nominal and interval-level responses to assess a person's engagement in pro-environmental behaviors. As a whole, Chronbach's alpha for the PEBS is somewhat low $(\alpha=.63)$. Due to the somewhat low reliability of the overall scale and subscales, I developed a single "proenvironmental behavior' score for each participant. The higher the score (range 28-65), the higher level of engagement in pro-environmental behavior. The score was then standardized using a z-score to allow for comparison to the other variables $(\mathrm{M}=0, \mathrm{SD}=$ 1). Pearson's r correlation analysis was then conducted to demonstrate the relationship between the standardized pro-environmental behavior item and online activism, as well as the relationship between pro-environmental behavior and varying motivations for social media use. 
Online Activism Analysis. The questions pertaining to the measures of online activism are on a Likert-type scale (1= "strongly disagree" to $5=$ "strongly agree"). The OSAS was found to have strong scale reliability, so the variables were combined into a single index $(\mathrm{M}=2.80, \mathrm{SD}=1.02)$

Social Media Motivation Analysis. The motivation for social media use scale by AlMenayas (2015) was divided into five subscales. Because each subscale demonstrated high reliability, each one was converted into a single subscale score for each participant: entertainment $(M=3.50, S D=1.030)$, personal utility $(M=2.56, S D=1.120)$, information seeking $(\mathrm{M}=3.28, \mathrm{SD}=1.200)$, convenience $(\mathrm{M}=3.15, \mathrm{SD}=1.263)$, and altruism $(M=2.66, S D=1.313)$.

Table 1

\begin{tabular}{|r|c|c|c|}
\hline \multicolumn{4}{|c|}{ Pro-environmental Behavior Subscale Statistics } \\
\hline & $\mathrm{M}$ & $\mathrm{SD}$ & $\alpha$ \\
\hline Total Scale & 2.60 & 0.371 & 0.63 \\
\hline Conservation & 3.65 & 0.623 & 0.60 \\
\hline Environmental Citizenship & 2.09 & 0.431 & 0.86 \\
\hline Food & 1.66 & 0.664 & 0.27 \\
\hline Transportation & 2.54 & 0.894 & 0.52 \\
\hline
\end{tabular}




\section{Results}

RQ1 questions the relationship between online activism and pro-environmental behavior. A Pearson's r correlation analysis was conducted to find that there is a significant positive correlation between the variables, $(r=.240, p=.002)$.

RQ2 examines the relationship between pro-environmental behavior and social media use for the purpose of entertainment. A Pearson's r correlation analysis was conducted to find that the relationship is not significant $(\mathrm{r}=.095, \mathrm{p}=.229)$.

RQ3 examines the relationship between pro-environmental behavior and social media use for the purpose of personal utility. A Pearson's r correlation analysis was conducted to find that the relationship is not significant $(\mathrm{r}=.090, \mathrm{p}=.253)$.

RQ4 examines the relationship between pro-environmental behavior and social media use for the purpose of information seeking. A Pearson's $r$ correlation analysis was conducted to find that the relationship is not significant $(\mathrm{r}=.028, \mathrm{p}=.720)$.

RQ5 examines the relationship between pro-environmental behavior and social media use for the purpose of convenience. A Pearson's r correlation analysis was conducted to find that the relationship is not significant $(\mathrm{r}=.063, \mathrm{p}=.422)$.

RQ6 examines the relationship between pro-environmental behavior and social media use for the purpose of altruism. A Pearson's $r$ correlation analysis was conducted to find that there is a significant positive correlation between the variables $(r=.202, p=$ $0.01)$. 


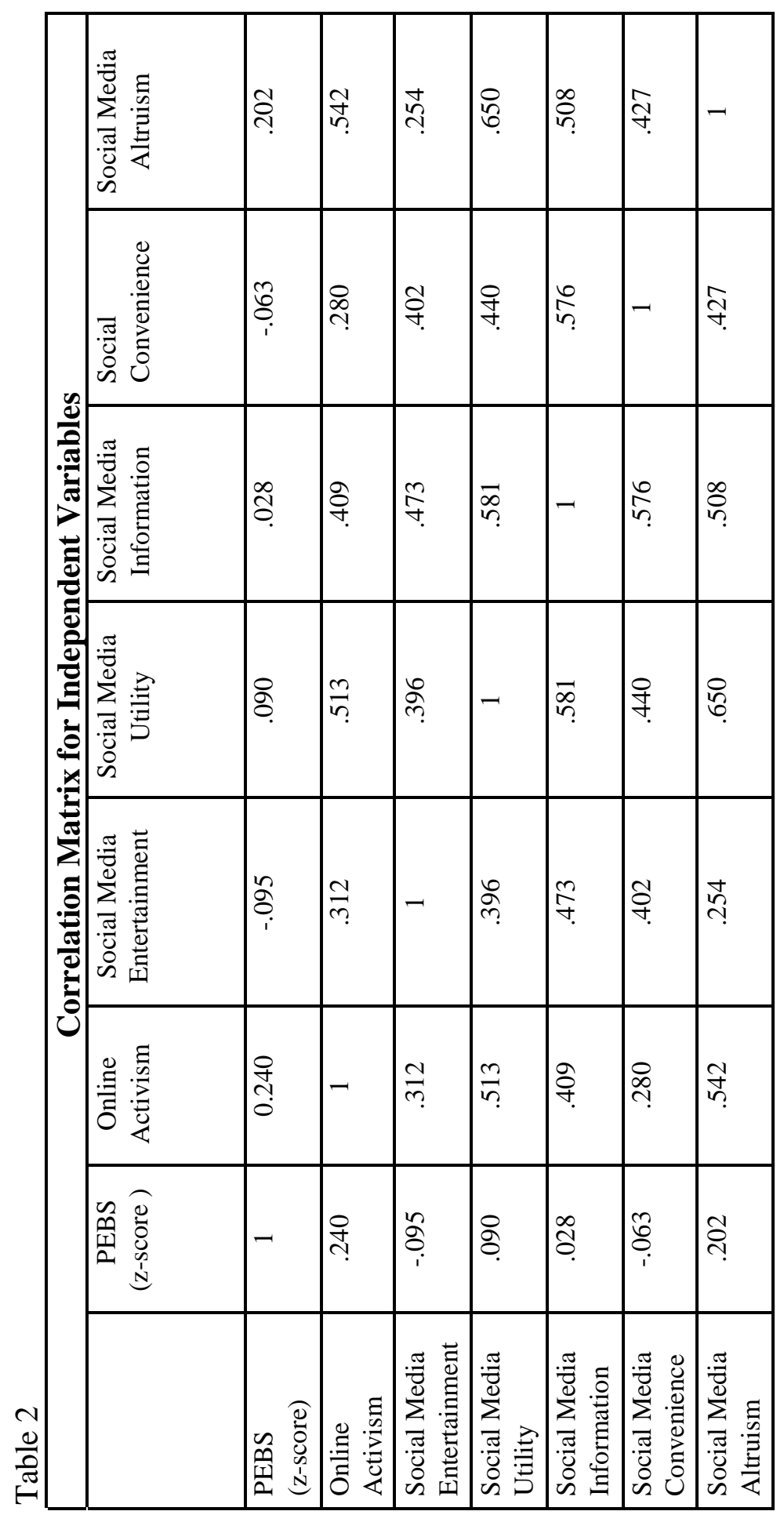




\section{Discussion}

This study focused on the relationships between online activism and participation in other meaningful forms of support towards a social movement. This study builds on the ideas examined by Kristofferson et al. (2014), which considers whether or not participation in meaningful forms of support is correlated with behaviors that constitute online activism. The findings in past research have been mixed, and therefore prior data has yet to clarify whether the relationship is complementary or if online activism performs the role of replacing other forms of support, an idea labeled as replacement thesis (Morozov, 2009; Cabrera et al., 2017).

My data revealed a significant positive association between participation in online activism, such as engagement in conversations related to social or political issues, and pro-environmental behavior, such as eating less meat, driving less, and taking efforts to conserve resources. My findings, therefore, suggest that the two behaviors correlate with one another, highlighting the engagement levels and activist involvement of people who participate in online activism. This data aligns with prior findings that show correlations between online activism and other forms of offline participation (Li et al., 2020; Onuch, 2014; Vie, 2014; Šte`ka \& Mazák, 2014).

These results do not align with prior work that has shown no relationship between online activism and pro-environmental behavior (Kristofferson et al., 2014; Morozov, 2009; King, 2006). Kristofferson et al. (2014) In other words, the criticism towards people who engage in online activism using social media as being "slacktivists" or "lazy activists" may not be warranted. These results run counter to Morozov’s (2009) replacement thesis. In replacement thesis, acts that involve a low degree of effort or 
commitment to a cause such as liking and sharing on social media replace actions that take more effort. The correlation between online activism and pro-environmental behavior would need to be negative in order to support replacement thesis; thus, the data supports the notion that the relationship between online activism and pro-environmental behavior is complementary.

An important consideration is the way that the relationship between online activism and pro-environmental behavior has been reported over time. Studies done within the last seven years are more likely to report a correlation between the two variables, such as the work of Li et al. (2020), Onuch (2014), Vie, (2014), and Šte ka and Mazák (2014). Half of the studies that show no relationship between pro-environmental behavior or other forms of activism and online activism were conducted before 2010, such as by Morozov (2009) and King (2006). The correlation found between the variables is likely being affected by the shifting contexts of internet usage, and the way that social media has grown in its presence in everyday life (Castells, 2015). Even more recent research is needed to consider the social-technological context of social media usage and online activism during the time of the COVID-19 pandemic. Because people are restricted in some forms of offline activism and are leaving their homes less, their participation on social media with social causes has shifted (Grant \& Smith, 2021).

The relationship between pro-environmental behavior and using social media for the purpose of information seeking was not found to be significant. Zhang and Skoric (2018) theorize that information sharing through social media explains higher engagement in certain pro-environmental behaviors such as green purchasing behaviors; my findings challenge this proposed explanation. Furthermore, my results do not align 
with Yang, Kahlor, and Griffin's (2014) findings that show people who share information on social media about environmentally-friendly products are motivated by

information-seeking. One potential reason is that people may have other sources of media they use for the purpose of information seeking and that their social media use is motivated primarily by other factors, but more research is needed to explain this discrepancy in the findings. These findings align with the primary focus of the uses and gratifications theory, which suggests that people have different motivations for media use and engaging in media is a way to fulfill their needs (Al-Menayas, 2015).

The relationship between pro-environmental behavior and using social media for the purpose of entertainment was not found to be significant. Very little, if any, research has previously explored this relationship. Therefore, future research should focus on ways in which entertainment media can be utilized to improve engagement in

pro-environmental behavior as a way to engage individuals who use social media for the primary purpose of entertainment. Additionally, the relationship between

pro-environmental behavior and using social media for the purpose of convenience was not found to be significant. This relationship has not been explored by prior research, therefore, there is very little empirical evidence to explain this relationship. Future research should examine how to engage people who use social media out of convenience, which in other words refers to them using it because it's free and as a way to "kill time" (Al-Menayas et al., 2017)

The relationship between pro-environmental behavior and using social media for the purpose of personal utility was not found to be significant. There is little research to compare these findings to or offer potential explanations, however Yang et al. (2014) find 
that information sharing online about climate change is motivated by social values. This includes similar motivations to personal utility, such as answering others questions or engaging in conversations. While social values and social media use for personal utility are distinct concepts in the way they were operationalized in the piece by Yang et al.

(2014) compared to the current study, this could suggest a reason to expect a possible positive relationship between using social media for personal utility and proenvironmental behavior. Given that the current study did not find a relationship, future research should explore these dynamics.

While the relationships between pro-environmental behavior and many of the types of motivations for social media use were not found to be significant, one was shown to be significant. The data revealed that people who use social media for the purpose of altruism are positively associated with having higher levels of engagement in pro-environmental behavior. This finding adds support to the relationship discovered by Zhang and Skoric (2018). They found that a person's altruistic motivation for using social media is correlated with their engagement in pro-environmental behavior and policy. Another study by Yang et al. (2014) explored the relationship between motivations for social media use and engagement in sharing information about climate change. They discover that people who use social media for the purpose of altruism are more likely to engage in information sharing. This relationship points to the notion that people who care about the environment are also likely to care about helping others, and those values motivate them to use social media as a way to connect with others. For a summary of covariance of all independent variables, see the correlation matrix in the Appendix. 


\section{Limitations \& Future Research}

This study has several limitations. First, the participants were recruited from students in undergraduate-level communication courses at a single university in the Pacific Northwest. Due to the method of recruitment and the small sample size $(n=163)$ this is not a representative sample of a broader public. Therefore, the findings cannot be generalized beyond the study participants. Furthermore, the sample was majority white, female respondents between 18-24 years of age. These participants belong to populations more likely to have pro-environmental values and access to a wider range of behavior choices, such as food or transportation options (e.g. Dietz, Kalof, \& Stern, 2002)

Another limitation is the possible covariance between the environmental citizenship subscale within Markle's (2013) pro-environmental behavior scale (PEBS) and the activities included in the online activism scale (OSAS) by Yankah et al. (2017). A correlation analysis reveals that there is a significant positive correlation between these scales $(\mathrm{r}=.254, \mathrm{p}=.001)$. This relationship may be strengthening the positive correlation found between the PEBS and the OSAS. A second limitation related to the scales is the moderate reliability of the PEBS as a whole $(\alpha=.61)$, and the low reliability for certain subscales such as environmental citizenship $(\alpha=.28)$ and transportation $(\alpha=.56)$. These subscales were included in the analysis due to the unique nature of

pro-environmental behavior; because it includes such a wide range of behaviors, engagement in one kind of behavior does not predict engagement in other subsets of behaviors. The original scale by Markle (2013) also had lower than optimal reliability ( $\alpha$ $=.76$ ), however, this scale was developed through a meta-analysis of other scales for 
measuring pro-environmental behavior, and therefore is a comprehensive measure. I analyzed the responses to this scale as a "score," rather than an average/index for three reasons. First, low reliability of the subscales indicated that they should not be used together as they were not measuring the constructs identified when combined together (e.g. transportation). Second, environmental behavior is not a monolith, as engaging in one behavior (e.g. taking public transit) does not guarantee engaging in another (e.g. carpooling), so there is little reason to expect those scale items to be highly reliable. Third, each item is in and of itself a pro-environmental behavior. As such, creating a 'score' for participants more accurately captures the rates of pro-environmental behavior for participants. That said, future studies attempting to use Markle's (2013) PEBS as a singular variable should examine the reliability in larger samples and make efforts to improve the overall reliability of this scale.

This study relied on self-report to assess pro-environmental behavior and social media use, rather than objective observation. Given the possibility of a social desirability response (Frauke, Stanley, \& Roger, 2008), future studies should examine pro-environmental behavior in other ways to avoid false reporting. Finally, this study used correlation analyses to assess the relationships. While illuminating the extent to which these variables relate, correlation does not establish causation. It is not possible to know, based on the current study, whether online activism leads to pro-environmental behavior, or whether engaging in pro-environmental behavior leads to online activism. Future research should consider the effects of these relationships in other contexts. At the time of writing, a prominent social movement is the Black Lives Matter movement, which has been both developed and gained momentum through widespread 
online activism (Carney, 2016). Future research should explore the relationship between activities involved in showing support for Black Lives Matter online and outcomes of the movement, such as prominence in mass media discourse or policy change. Another consideration about this study and future research is that this research was collected during the COVID-19 pandemic. This means that social media use, online activism activities, and the motivations for using social media may be altered by the current conditions of our social world, such as social distancing and government-mandated quarantines (Saud, Mashud, \& Ida, 2020).

The analyses performed in the current study looked only at the relationship between motivations for social media use and pro-environmental behavior. Because prior research has shown that people have a multitude of motivations for using social media (Yankah et al., 2017), this study did not categorize participants according to their primary motivation for social media use. While the data presents social media use as being motivated by one variable at a time, in reality, the motivation is multifaceted. Future research should examine alternative methods of categorizing people according to their social media use movations, to explore the extent to which primary motivators predict pro-environmental behavior, and better capture the complex nature of social media use motivation. 


\section{Conclusion}

Human activity has caused widespread devastation to the environment; because present actions will contribute to its preservation or further destruction, it is critical that individuals change their behavior in ways that are sustainable. Former research shows that pro-environmental behavior is a key factor in addressing pressing environmental problems. In order to understand ways to promote engagement in pro-environmental behavior, science needs to explore its interaction with other variables, highlighting key relationships. Prior literature shows a connection between pro-environmental behavior and online activism, and while former literature points to a correlation between these variables, research is relatively limited. Therefore, online activism has received criticism for the suspected role it plays in negating other meaningful forms of activism or participation in a movement. Among other results, this study demonstrates a positive relationship between online activism and pro-environmental behavior, and shows that altruism as a motivation for social media use is uniquely related to pro-environmental behavior, compared to other motivations. 


\section{References}

Al-Menayes, J. J. (2015). Motivations for Using Social Media: An Exploratory Factor Analysis. International Journal of Psychological Studies, 7(1), p 43. https://doi.org/10.5539/ijps.v7n1p43

Amant, K. (2017). Online networks, social media, and communication design. Communication Design Quarterly Review, 4(2), 10-11.

Balunde, A., Perlaviciute, G., \& Steg, L. (2019). The Relationship Between People's Environmental Considerations and Pro-environmental Behavior in Lithuania. Frontiers in Psychology. Gale Academic OneFile. http://link.gale.com/apps/doc/A602778784/AONE?u=s1185784\&sid=zotero\&xid $=\mathrm{c} 0 \mathrm{c} 4 \mathrm{f} 39 \mathrm{f}$

Berdyaev, N. (1960) [first published 1948; first edition published 1937]. The origin of Russian communism (new ed.). Ann Arbor, Michigan, United States: University of Michigan Press.

Bleys, B., Defloor, B., Van Ootegem, L., \& Verhofstadt, E. (2018). The environmental impact of individual behavior: Self-assessment versus the ecological footprint. Environment and Behavior, 50(2), 187-212.

https://doi.org/10.1177/0013916517693046 
Blok, V., Wesselink, R., Studynka, O., \& Kemp, R. (2015). Encouraging sustainability in the workplace: a survey on the pro-environmental behaviour of university employees. Journal of Cleaner Production, 106, 55-67. https://doi.org/10.1016/i.jclepro.2014.07.063

Bouleau, G. (2019). Politicization of ecological issues: From environmental forms to environmental motives (Interdisciplinarity, science and humanities series). London, UK: Hoboken, NJ: ISTE; Wiley.

Cabrera, N., Matias, C., \& Montoya, R. (2017). Activism or slacktivism? The potential and pitfalls of social media in contemporary student activism. Journal of Diversity in Higher Education, 10(4), 400-415. http://dx.doi.org.proxy.lib.pdx.edu/10.1037/dhe0000061

Carney, N. (2016). All lives matter, but so does race. Humanity \& Society, 40, 180-199. doi:10.1177/0160597616643868

Castells, M. (2015). Networks of outrage and hope: Social movements in the Internet age (Second ed.). Cambridge, UK; Malden, MA: Polity Press.

Correa, T., Hinsley, A., \& De Zuniga, H. (2010). Who interacts on the web? The intersection of users' personality and social media use. Computers in Human Behavior, 26, 247-253.

Christensen, H. (2011). Political activities on the internet: Slacktivism or political participation by another means? First Monday, 16, 1-10. http://dx.doi.org/10.5210/fm.v16i2.3336 
Dietz, T., Kalof, L., \& Stern, P. C. (2002). Gender, values, and environmentalism. Social Science Quarterly, 83(1), 353-364.

Fernandez Sainz, J. (2013). Environmental knowledge and other variables affecting roenvironmental behaviour: comparison of university students from emerging and advanced countries. Journal of Cleaner Production, 61(C), 130-138. https://doi.org/info:doi/

Fleming, J., \& Knorr, B. (n.d.) "History of the Clean Air Act". American Meteorological Society. https://www.ametsoc.org/sloan/cleanair/

Gore, T., Alestig, M., \& Ratcliff, A. (2020). Confronting carbon inequality: Putting climate justice at the heart of the COVID-19 recovery. Oxfam. https://oxfamilibrary.openrepository.com/bitstream/handle/10546/621052/mb-con fronting-carbon-inequality-210920-en.pdf

Grant, P., \& Smith, H. (2021). Activism in the time of COVID-19. Group Processes \& Intergroup Relations, 24(2), 297-305.

Griffin, P. (2017). CDP carbon majors report 2017. The Carbon Majors Database. https://6fefcbb86e61af1b2fc4-c70d8ead6ced550b4d987d7c03fcdd1d.ssl.cf3.rackc dn.com/cms/reports/documents/000/002/327/original/Carbon-Majors-Report-201 7.pdf?1501833772 
Han, R., \& Xu, J. (2020). A comparative study of the role of interpersonal communication, traditional media and social media in pro-environmental behavior: A China-based study. International Journal of Environmental Research and Public Health, 17(6), 1883-1904.

Harlow, S. (2012). Social media and social movements: Facebook and an online Guatemalan justice movement that moved offline. New Media \& Society, 14, 225243. doi:10.1177/1461444811410408

Hemp, P. (2009). Death by information overload. Harvard Business Review, 87, 82-89.

Jones, C. (2015). Slacktivism and the social benefits of social video: Sharing a video to 'help' a cause. First Monday. http://dx.doi.org/10.5210/fm.v20i5.5855

Jost, J. T., Barberá, P., Bonneau, R., Langer, M., Metzger, M., Nagler, J., ... \& Tucker, J. A. (2018). How social media facilitates political protest: Information, motivation, and social networks. Political Psychology, 39, 85-118.

Junco, R. (2012). The relationship between frequency of Facebook use, participation in Facebook activities, and student engagement. Computers \& Education, 58(1), 162-171. https://doi.org/10.1016/j.compedu.2011.08.004

Kaiser, F., \& Fuhrer, U. (2003). Ecological behavior's dependency on different forms of knowledge. Applied Psychology, 52(4), 598-613. https://doi.org/10.1111/1464-0597.00153

Karpf, D. (2012). The MoveOn effect: The unexpected transformation of American political advocacy. New York, NY: Oxford University Press. http://dx.doi.org/10.1093/acprof:oso/978019 9898367.001.0001 
King, S. (2006). Pink Ribbons, Inc.: Breast Cancer and the Politics of Philanthropy, Minneapolis: University of Minnesota Press.

Kristofferson, K., White, K., \& Peloza, J. (2014). The nature of slacktivism: How the social observability of an initial act of token support affects subsequent prosocial action. Journal of Consumer Research, 40(6), 1149-1166.

https://doi.org/10.1086/674137

Frauke K., Stanley P., \& Roger T.. (2008). Social desirability bias in CATI, IVR, and Web Surveys: The effects of mode and question sensitivity. Public Opinion Quarterly, 72(5), 847-865. https://doi.org/10.1093/poq/nfn063

Laroche, M., Bergeron, J., \& Barbaro-Forleo, G. (2001). Targeting consumers who are willing to pay more for environmentally friendly products. The Journal of Consumer Marketing, 18(6), 503-520. https://doi.org/10.1108/eum0000000006155

Larson, L. R., Stedman, R. C., Cooper, C. B., \& Decker, D. J. (2015). Understanding the multi-dimensional structure of pro-environmental behavior. Journal of Environmental Psychology, 43, 112-124.

Leary, M., \& .Kowalski, R. (1990) Impression management: A literature review and two-component model. Psychological Bulletin, 107 (1), 34-47.

Lee, Y., Kim, S., Kim, M., \& Choi, J. (2014). Antecedents and interrelationships of three types of pro-environmental behavior. Journal of Business Research, 67(10), 20972105. https://doi.org/10.1016/i.jbusres.2014.04.018 
Lehman, P., \& Geller, E. (2004) Behavior analysis and environmental protection: accomplishments and potential for more. Behav. Soc. Iss. 13, 13-33. https://doi.org/10.5210/bsi.v13i1.33

Li, M., Turki, N., Izaguirre, C., DeMahy, C., Thibodeaux, B., \& Gage, T. (2021). Twitter as a tool for social movement: An analysis of feminist activism on social media communities. Journal of Community Psychology, 49(3), 854-868. https://doi.org/10.1002/jcop.22324

Loader, B., \& Mercea, Dan. (2012). Social media and democracy: Innovations in participatory politics (Routledge research in political communication; 6). London; New York: Routledge.

Markle, G. L. (2013). Pro-environmental behavior: Does it matter how it's measured? Development and validation of the pro-environmental behavior scale (PEBS). Human Ecology, 41(6), 905-914. JSTOR.

McCafferty, D. (2011). Activism Vs. Slacktivism. Communications Of The ACM, 54(12), 17-19.

Meraz, S. (2009). Is there an elite hold? Traditional media to social media agenda setting influence in blog networks. Journal of Computer-Mediated Communication, 14, $682-707$. 
Moisander, J. (2007). Motivational complexity of green consumerism. International Journal of Consumer Studies, 31(4), 404-409.

Morozov, E. (2009). The net delusion: The dark side of internet freedom. New York, NY: Public Affairs

Murthy, D. (2018). Introduction to social media, activism, and organizations. Social Media + Society, 4(1), 2056305117750716. https://doi.org/10.1177/2056305117750716

Nordlund, A. M., and Garvill, J. (2002). Value structures behind pro-environmental behavior. Environ. Behav. 34, 740-756. doi: 10.1177/001391602237244

Onokala, U., Banwo, A., \& Okeowo, F. (2018). Predictors of Pro-Environmental Behavior: A Comparison of University Students in the United States and China Journal of Management and Sustainability, 8, 127. https://doi.org/10.5539/jms.v8n1p127

Onuch, O. (2014, January 2). Social networks and social media in Ukrainian “Euromaidan" protests. Washington Post. Retrieved from https://www.washingtonpost.com/news/monkey-cage/wp/2014/01/02/social-netw orks-and-social-media-in-ukrainian-euromaidan-protests-2/

Pop, R., Săplăcan, Z., \& Alt, M. (2020). Social media goes green-The impact of social media on green cosmetics purchase motivation and intention. Information (Basel), 11(9), 447. https://doi.org/10.3390/info11090447 
Quan-Haase, A., \& Young, A. (2010). Uses and Gratifications of social media: A comparison of Facebook and instant messaging. Bulletin of Science, Technology \& Society, 30(5), 350-361. doi:10.1177/0270467610380009

Raacke, J., \& Raacke, J.B. (2008) Why people use social media: A uses and gratifications approach. Cyberpsychology \& Behavior, 11(2). https://doi.org/10.1108/QMR-06-2013-0041

Saud, M., Mashud, M., \& Ida, R. (2020). Usage of social media during the pandemic: Seeking support and awareness about COVID-19 through social media platforms. Journal of Public Affairs, 20(4), e02417-n/a. https://doi.org/10.1002/pa.2417

Scheffer, V. (1991). The shaping of environmentalism in America. Seattle: University of Washington Press.

Šte`ka, V., \& Mazák, J. (2014). Whither slacktivism? Political engagement and social media use in the 2013 Czech parliamentary elections. Cyberpsychology, 8(3) http://dx.doi.org/10.5817/ CP2014-3-7

Steg, L., Bolderdijk, J. W., Keizer, K., and Perlaviciute, G. (2014a). An integrated framework for encouraging pro-environmental behaviour: the role of values, situational factors and goals. J. Environ. Psychol. 38, 104-115. doi: 10.1016/j. jenvp.2014.01.002

Steg, L., Perlaviciute, G., Van der Werff, E., and Lurvink, J. (2014b). The significance of hedonic values for environmentally relevant attitudes, preferences, and actions. Environmental Behavior. 46, 163-192. doi: 10.1177/0013916512454730 
Steg, L., De Groot, J. I., Dreijerink, L., Abrahamse, W., and Siero, F. (2011).

General antecedents of personal norms, policy acceptability, and intentions: the role of values, worldviews, and environmental concern. Soc. Nat. Resour. 24, 349367. doi: 10.1080/08941920903214116

Steg, L., and De Groot, J. (2012). "Environmental Values," in The Oxford Handbook of Environmental and Conservation Psychology. 81-91 New York: New York.

Steg, L., \& Vlek, C. (2009). Encouraging pro-environmental behaviour: an integrative review and research agenda. Journal of Environmental Psychology, 29, 309-317.

Stern, P. C. (1999). Information, incentives, and pro-environmental consumer behavior. Journal of Consumer Policy, 22(4), 461-478.

Stern, P. C. (2000). Toward a coherent theory of environmentally significant behavior. Journal of Social Issues, 56(3), 407-424.

UNICEF Sweden (2013), “'Likes Don’t Save Lives’ Promotional Campaign,” https://www.youtube.com/watch?v=2 M0SDk3ZaM

Vicente-Molina, M. A., Fernández-Sáinz, A., \& Izagirre-Olaizola, J. (2013).

Environmental knowledge and other variables affecting pro-environmental behaviour: Comparison of university students from emerging and advanced countries. Journal of Cleaner Production, 61, 130-138.

https://doi.org/10.1016/i.jclepro.2013.05.015

Vie, S. (2014). In defense of "slacktivism": The Human Rights Campaign Facebook logo as digital activism. First Monday. Advance online publication. http://dx.doi.org/10.5210/fm.v19i4.4961 
Worland, J. (2016). How activists are using Facebook check-in to help Dakota access pipeline protesters. Time. Retrieved from http://time.com/4551866/facebook-dakotaaccess- pipeline-check-in/

Yankah, S., Adams, K., Grimes, L., \& Price, A. (2017). Age and Online Social Media Behavior in Prediction of Social Activism Orientation. The Journal of Social Media in Society, 6(2), 56-89. Retrieved from https://thejsms.org/index.php/TSMRI/article/view/299

Yang, Z. Janet, Kahlor, Lee Ann, \& Griffin, Darrin J. (2014). I Share, Therefore I Am: A U.S.-China Comparison of College Students' Motivations to Share Information About Climate Change. Human Communication Research, 40(1), 112-135. https://doi.org/10.1111/hcre.12018

Zhang, N. \& Skoric, M. (2018). Media use and environmental engagement: Examining differential gains from news media and social media. International Journal of Communication (Online), 380-403. 
Appendix A

\section{Pro-Environmental Behavior Scale by Markle (2013)}

\section{A. Conservation:}

1. How often do you turn off the lights when leaving a room?

1 = "never", 2= "rarely", 3= "sometimes", 4 = "usually", 5= "always"

2. How often do you switch off standby modes of appliances or electronic devices?

1 = "never", 2= "rarely", 3= "sometimes", 4 = "usually", 5= "always"

3. How often do you cut down on heating and air conditioning to limit energy use?

1 = "never", 2= "rarely", 3= "sometimes", 4 = "usually", 5= "always"

4. How often do you turn off the TV when leaving a room?

1 = "never", 2= "rarely", 3= "sometimes", 4 = "usually", 5= "always"

5. How often do you limit your time in the shower to conserve water?

1 = "never", 2= "rarely", 3= "sometimes", 4 = "usually", 5= "always"

6. How often do you wait until you have a full load to use the washing machine or dishwasher?

1 = "never", 2= "rarely", 3= "sometimes", 4 = "usually", 5= "always"

7. At which temperature do you wash most of your clothes?

$1=$ "hot", 3 = "warm", 5= "cold"

\section{B. Environmental Citizenship}

1. Are you currently a member of an environmental, conservation, or wildlife protection group?

$1=$ "no", 2 = "yes" 
2. During the past year, have you contributed money to an environmental, conservation, or wildlife protection group?

$1=$ "no", $2=$ "yes"

3. How frequently do you watch television programs, movies, or internet videos about environmental issues?

1 = "never", 2= "rarely", 3= "sometimes", 4 = "usually", 5= "often"

4. How often do you talk to others about their environmental behavior?

$1=$ "never", 2= "rarely", 3= "sometimes", 4 = "usually", 5= "often"

5. During the past year, have you increased the amount of organically grown fruits and vegetables you consume?

$1=$ "no", 2= "yes"

6. Please answer the following question based on the vehicle you drive the most often: Approximately how many miles per gallon does the vehicle get?

$1=$ "24 or less", $1=$ " $25-29 " 1=$ " $30-34 ”, 1=$ " $35-39 ”, 5=$ " 40 or more"

\section{Food}

1. During the past year have you decreased the amount of beef you consume?

$1=$ "no", 5= "yes, 5= "I do not eat beef/pork/poultry"

2. During the past year have you decreased the amount of poultry you consume? $1=$ "no", 5= "yes, 5= "I do not eat beef/pork/poultry"

3. During the past year have you decreased the amount of pork you consume? 


\section{Transportation}

1. During the past year how often have you car-pooled?

$1=$ "never", $3=$ "occasionally", 5= "frequently"

2. During the past year how often have you used public transportation?

$$
1=\text { "never", } 3=\text { "occasionally", 5= "frequently" }
$$

3. During the past year how often have you walked or cycled instead of driving?

$$
1=\text { "never", } 3=\text { "occasionally", 5= "frequently" }
$$




\section{Appendix B}

\section{Online Social Activism Scale (OSAS) Items by Yankah et al. (2017)}

1. I frequently express my social and/or political views on social networking sites.

2. I have used social networking sites to make informative posts about a social and/or political cause.

3. I frequently comment on social and/or political posts on social networking sites.

4. I rarely participate in conversations about social and/or political issues on social networking sites.

5. I frequently post about social and/or political topics on social networking sites.

6. I frequently "like" social and/or political posts on social networking sites.

7. I often read social and/or political posts on social networking sites.

8. I seldom comment on social and/or political posts on social networking sites.

9. I often "share" or "retweet" social and/or political posts on social networking sites.

10. I rarely "like", "favorite", or "save", social or political posts from social networking sites.

11. I often update my status on social media sites with my views on current social and/or political issues.

12. I rarely initiate conversations about social and/or political issues on social networking sites.

13. I have joined or followed social and/or political groups on social networking sites. 
14. I have made a financial contribution to a social or political campaign because of content from a social networking site.

15. Posts on social networking sites about social and/or political issues would not influence my decision to contribute financially to a campaign or cause.

16. I rarely use my social media accounts to show support for social and/or political causes.

17. I "follow "or regularly check profiles or pages that frequently post social and/or political content.

18. I often support social or political campaigns by sharing information on social networking sites.

19. I do not "follow" or "add" people/pages that frequently post social and/or political content.

20. I often participate in conversations about social and/or political issues on social networking sites.

21. I often initiate conversations about social and/or political issues on social networking site

All items answered on the following scale:

$1=$ strongly disagree, $2=$ disagree, $3=$ somewhat disagree, $4=$ neither agree or disagree, $5=$ somewhat agree, $6=$ agree, $7=$ strongly agree 
Appendix C

\section{Motivation for Social Media Use Scale by Al-Menayes (2015):}

\section{Entertainment:}

1. I use it to kill time.

2. When I have nothing else to do.

3. To occupy my time

4. Because it entertains me

5. Because I enjoy using it

\section{Personal Utility}

6. To join conversations

7. To join groups

8. I enjoy answering questions

9. To listen to others opinions

\section{Information Seeking}

10. For research and homework

10. To get free information

11. To search for information

12. To know what's going on

\section{Convenience}

13. Because it's free

14. It is easier than meeting

15. Others can answer anytime 


\section{Altruism}

16. To help others

17. To encourage others to do work.

All questions are to be answered on a 5 Likert scale

$1=$ not at all, 5= exactly 


\section{Appendix D}

\section{Social Media Frequency Scale by Junco (2012)}

"How frequently do you perform the following activities when you are on social media sites? "Facebook activity items were coded using a five-point, positively anchored Likert scale ranging from "Never" to "Very Frequently (close to $100 \%$ of the time)." For these analyses, "Never" was coded as 1; "Rarely (25\%)" as 2; "Sometimes (50\%)" as 3; "Somewhat frequently (75\%)" as 4; and "Very frequently (close to $100 \%$ of the time)" as

5.

Playing games (FarmVille, MafiaWars, etc.)

Posting status updates

Sharing links

Sending private messages

Commenting (on statuses, wall posts, pictures, etc.)

Chatting on Facebook chat

Checking in to see what someone is up to

Creating or RSVPing to events

Posting photos

Tagging photos

Viewing photos

Posting videos 
Tagging videos

Viewing videos 
Appendix E

\section{Demographic Data}

\begin{tabular}{|c|c|}
\hline & s your a \\
\hline - & $18-24$ \\
\hline & $25-34$ \\
\hline & $35-44$ \\
\hline & $45-54$ \\
\hline - & $55-64$ \\
\hline - & $65-74$ \\
\hline & $75-84$ \\
\hline & 85 or 0 \\
\hline
\end{tabular}

What is your biological sex?

- $\quad$ Female

- $\quad$ Male

- $\quad$ Intersex

- $\quad$ Prefer not to answer

Which of the following best describes you?

- White

- $\quad$ Black or African American 
- $\quad$ American Indian or Alaska Native

- Asian

- $\quad$ Native Hawaiian or Pacific Islander

- Multiracial

- $\quad$ Other: (please specify

- $\quad$ Prefer not to answer 